\title{
Valuing Flexibility in the Migration to Flexible-grid Networks [Invited]
}

\author{
Mathieu Tahon, Sofie Verbrugge, Didier Colle, Mario Pickavet, Piet Demeester, Paul \\ Wright, Andrew Lord
}

\begin{abstract}
Increasing network demand is expected to put pressure on the available capacity in core networks. Flexible optical networking can now be installed to increase network capacity in light of future traffic demands. However, this technology is still in its infancy and might lack the full functionality that may appear within a few years. When replacing core network equipment, it is therefore important to make the right investment decision between upgrading towards flexiblegrid or fixed grid equipment. This paper researches various installation options using a techno-economic analysis, extended with real option insights, showing the impact of uncertainty and flexibility on the investment decision. By valuing the different options, a correct investment decision can be made.
\end{abstract}

Index Terms -flexible-grid; real option analysis; technoeconomics

\section{FUtURE EVOLUTIONS IN TELECOM CORE NETWORKS}

$\mathrm{N}_{\mathrm{e}}$ etwork demand is continuously growing, especially with the adoption of more bandwidth hungry applications by users in the access network, which obviously also translates in an increase of traffic in the metro and core networks. However, this increase in transported bits is not reflected in the revenues for network operators, since the average revenue per user remains flat. To maintain profitability, there is a pressure on network operators to decrease the average cost per transported bit. Typically, this cost reduction is achieved by installing cost efficient equipment and network architectures. Currently, in the core network, Dense Wavelength Division Multiplexing (DWDM) equipment tuned to the $50 \mathrm{GHz}$ ITU grid is used. However, with increasing traffic, the underlying assumption that spectrum requirements pose no restriction has been challenged. This will result in networks where the capacity in the core falls behind demand.

To meet the increased demand, the channel capacity will

Manuscript received March 29, 2013.

M. Tahon, S. Verbrugge, D. Colle, M. Pickavet and P. Demeester are with the Internet Based Communication Networks and Services (IBCN) group of the Information Technology Department of the Ghent University, Ghent, Belgium (mathieu.tahon@intec.ugent.be).

P. Wright and A. Lord are with British Telecom, Ipswich, United Kingdom need to be increased beyond the current $100 \mathrm{G}$ per channel, together with an increase of spectral efficiency. Additionally, the dynamic functionality of networks should be increased, allowing for dynamic re-optimization.

To achieve the goals stated above, spectral flexibility - or flexible-grid - has been identified as the key type of expected flexibility within DWDM systems. Present day DWDM systems operate under the Fixed Grid - or ITU G.694.1 grid, introduced in 2002 [1]. Multiplexers, optical network nodes and transponders are all tuned to this grid. The core network is based on IP offloading, transponders with fixed bit rate and modulation format. But traffic growth would require the use of several $10 \mathrm{G}$ or $40 \mathrm{G}$ channels between adjacent IP routers.

Flexible-grid, making the wavelength switched optical network (WSON) elastic by moving away from the ITU grid, can accommodate both sub- and super wavelength traffic. It allows an adjustable use of optical spectrum within a certain granularity. This granularity is the minimum bandwidth slot that can be switched in the optical spectrum (6.25 and $12.5 \mathrm{GHz}$ are possible) [2]. This technology is slowly coming available, and operators have to decide whether or not to install this flexible-grid capable equipment in their network.

However, various aspects influence this decision. First, under the current predicted traffic growth patterns, Fixed Grid DWDM equipment is expected to suffice for the next years, until the next replacement investment in the core network equipment. Additionally, since the Flexible-grid technology is still in its infancy, an installation today will be expensive or risk poor reliability [2,3]. Also, the performance of this equipment might still be lacking the full functionality that may appear later.

In order to make the correct investment decision, a techno-economic analysis is conducted for the future installations in the UK core network, as described in [4]. Two different aspects of the investment decision are studied. The first aspect comprises the trade-off between a Fixed Grid DWDM installation and Flexible-grid installation, taking into account that a migration towards Flexible-grid might be required for the Fixed Grid DWDM under high future traffic growth. The analysis is extended to indicate how uncertain future traffic evolution impacts the decision making process. Finally, through a real option analysis (ROA) [5], it is shown how flexibility in the decision making has value for an operator.

This paper aims at indicating how uncertainty and flexibility can impact the investment decisions for operators. 
Therefore, the authors have opted to only explore a limited number of possible installation options. For example, the installation of a fixed grid with $100 \mathrm{GHz}$ spacing, or overbuilding routes have not been included in the analysis. In reality, operators will also need to take these options in consideration, to make a correct investment decision.

In the next section, the different migration paths will be introduced and a standard techno-economic analysis will be performed. Secondly, the impact of uncertainty on the decision making process is indicated. Finally, a ROA is performed to show the importance of flexibility and how it influences the investment decision.

\section{REPLACING THE UK CORE NETWORK EQUIPMENT}

To assess the flexible-grid installation investment decision, a techno-economic case study analysis is conducted for the UK core network (Fig. 1). This network consists of 27 nodes and 40 edges. There is a distinction between the blue and yellow nodes in Fig. 1. The blue nodes represent the current core network nodes, while the yellow nodes are metro network nodes that have been incorporated in the analysis. In the model, the current traffic matrix of the UK core network is entered, together with a yearly traffic growth prediction of $37 \%$ for the entire network [6]. As a result, the model calculates the traffic for each sourcedestination path for the entire time period assessed in the model. Routing the traffic through the network allows to assess the required equipment in the different nodes, taking

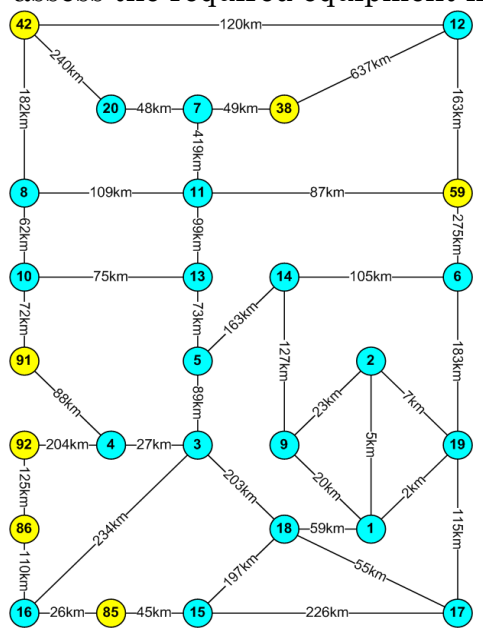

Fig. 1. The UK core reference network [4]

TABLE I

AVAILABLE MUXPONDERS [3]

\begin{tabular}{lccc}
\hline \hline \multicolumn{1}{c}{ Muxponder } & Reach & $\begin{array}{c}\text { Year } \\
\text { available }\end{array}$ & SCU \\
\hline $40 \mathrm{G}$, 4X10G (50GHz) & 2500 & 2012 & 5 \\
\hline $\begin{array}{l}\text { 100G, 10X10G } \\
(50 \mathrm{GHz})\end{array}$ & 2000 & 2012 & 13 \\
\hline $\begin{array}{l}\text { 100G, 10X10G, AUA } \\
40 \mathrm{G}(50 \mathrm{GHz})\end{array}$ & 2000 & 2012 & 16 \\
\hline $\begin{array}{l}400 \mathrm{G}, 10 \mathrm{X} 40 \mathrm{G} \\
(50 \mathrm{GHz})\end{array}$ & 150 & 2014 & 29 \\
\hline $\begin{array}{l}400 \mathrm{G}, 10 \mathrm{X} 40 \mathrm{G}, \mathrm{AUA} \\
\begin{array}{l}400 \mathrm{G}, 200 \mathrm{G}, 100 \mathrm{G} \\
(75 \mathrm{GHz})\end{array}\end{array}$ & 500 & 2014 & 46 \\
\hline
\end{tabular}

*AUA $=$ Also Usable As into account optical bypass. Since the typical replacement period for equipment is five years, this is the period we are interested in. Initially, two distinct scenarios can be assessed, analysing the investment in the WDM layer (Fig. 2). The first scenario evaluates the installation of a fixed grid core network, while the second studies the flexible-grid capable installation. However, these two installation options result in a loss of flexibility for the operator. When installing a fixed grid network today, the initial investment is low, but the operator risks either losing money, since he is not able to route all traffic, or he will be putting in a next generation DWDM network (presumably flexible-grid this time) earlier than he would have needed to, also leading to additional costs (fixed grid migrate scenario) under high traffic growth. On the other hand, he can opt to install a full flexible-grid network today. The advantages of such an installation are clear, under any future traffic growth; the operator is ready for it. However, under low traffic growth, a lot of money will be spent in vain, since the installed network equipment is overqualified for the current traffic matrix. Additionally, as was already indicated, the performance of current flexible-grid equipment might considerably improve during the following years. By installing this equipment today, the operator risks higher maintenance costs. And as the learning curve is followed, this will also result in a decrease of the cost for such equipment in the future.

However, there exists a third installation option which was not explored yet. This intermediate installation path offers future flexibility for the operator (flexible-grid migrate scenario). By installing flexible-grid capable nodes, but using fixed grid DWDM muxponders instead of flexiblegrid capable muxponders, the operator buys the flexibility for a cheaper migration towards flexible-grid if necessary. Additionally, since the nodes are used with fixed grid DWDM muxponders, the performance risk linked to the use of flexible-grid and the initial higher capital expenditures (CapEx) associated are decreased. The decision tree now looks as in Fig. 2.

Next to these three possible installation paths, the operator obviously has many other options. He can overbuild routes or install a fixed grid network with higher channel spacing. When the investment decision is made in practice by an operator, he should take all these options into account. We limit the scope of our study to these three

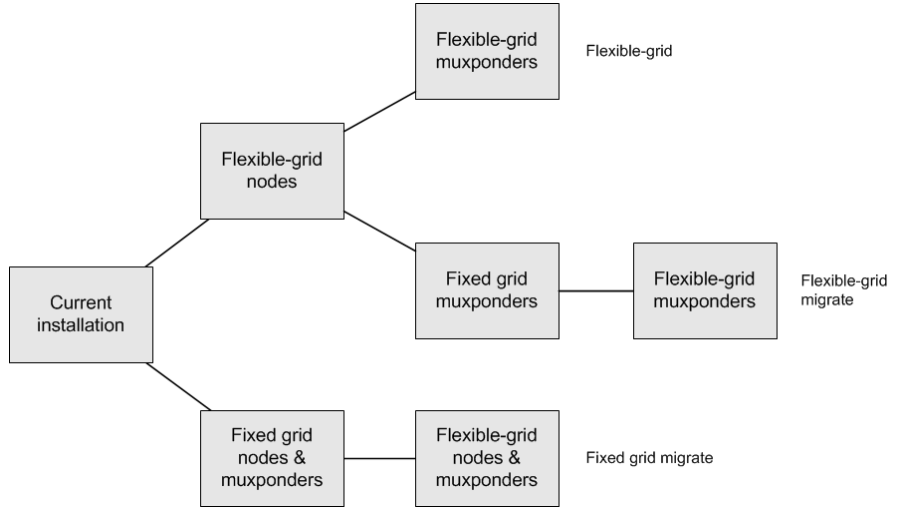

Fig. 2. Core network installation choices 
paths, as we aim at indicating the managerial flexibility thinking in telecom infrastructure investments.

Note that under the $37 \%$ yearly traffic growth prediction used, no migration to flexible-grid is required during the five year evaluation period. To assess the capital expenditures for both installations, the cost input from the STRONGEST CapEx model is used $[3,6]$.

Based on the traffic prognoses, a dimensioning is performed for the nodes and links in the network. As was indicated in [3], no standard node model exists for the WDM layer. The node is dependent on the nodal degree $\mathrm{N}$, and this rationale is also applied here. For an $\mathrm{N}=2$ an OADM, otherwise an OXC is modelled. In addition, based on the number of channels, the building blocks of the nodes vary, and can include Arrayed Waveguide Grating (AWG) or Wavelength Selective Switches (WSS). Currently the modelled nodes are not contentionless or directionless [7]. These nodes consist of wavelength selective switches (WSS) and amplifiers. Their amount is based on the node degree. We refer to [3] for a more detailed description of the node model.

Based on the traffic matrix and its expected evolution, the amount of muxponders for each source-destination pair are calculated. For example, a link with a demand of 30Gbps will result in the installation of a $40 \mathrm{G}$ (line rate), 4X10G (client requirements), $2500 \mathrm{~km}$ (reach) muxponder. Traffic of $120 \mathrm{Gbps}$ requires one $100 \mathrm{G}, 10 \mathrm{X} 10 \mathrm{G}, 2000 \mathrm{~km}$ and one $40 \mathrm{G}$, 4X10G, 2500km muxponder. With 400G muxponders only becoming available later during the project lifetime, these can only be installed from that year on, in the selected scenarios from above (Table I). This means that once 400G muxponders are available, a link which initially required four 100G muxponders could then have a 400G, 10X40G, $150 \mathrm{~km}$ muxponder. The operator can thus make the choice between installing an additional parallel 100G path, or replacing the parallel paths with one high capacity path. Here, it is assumed that this migration is performed. Of course, this installation can only be made if the reach constraint of the specific muxponder is satisfied. In addition, when muxponders are replaced by higher capacity muxponders, the initial expense for the first muxponder is not refunded. This calculation results in a number of muxponders required on the start and end node of every link. From this number of muxponders, it is straightforward to calculate the total number of muxponders and wavelengths required per node. The model is extended with three other aspects. As optical bypass is used, regenerators need to be included. For each muxponder, a comparable regenerator is available in the model. Their cost is 1.6 times higher than the comparable muxponder [3]. Secondly, amplifiers are modelled every $80 \mathrm{~km}$. The cost of the various types of equipment is expressed in STRONGEST Cost Units (SCU). One SCU represents the cost of a 10G WDM transponder, with a reach of $750 \mathrm{~km}$. Notice that for both DWDM and flexible-grid equipment, a cost erosion factor is included. For DWDM, this cost erosion is currently estimated at $10 \%$, while it is put at $15 \%$ for the flexible-grid equipment. The cost erosion for amplifiers was considered equally; as this is equipment is identical for both systems. This reflects the lower maturity of flexible-grid compared to DWDM. These numbers are based on the extended learning curve [8]. It allows modelling the cost evolution of components based on time, and not on the number of units produced. This makes it more suited for the prediction of cost evolution.

Thirdly, to allow for a fair comparison of the different migration paths, an operational cost for energy was added to the model. The energy use of different muxponders is included, based on industry insight.

In Table II, the total cost (in SCU) can be found for the three scenarios. The total cost of the fixed grid scenario and flexible-grid migrate scenario is considerably lower than the flexible-grid installation, as is to be expected. In [3], it was stated that flexible-grid equipment is about 1.3 times more expensive than fixed grid equipment. Here, a full flexiblegrid installation is 2.5 times more costly. This difference with [3] is driven by the overdimensioning of the flexible grid network for the current traffic matrix. The operator uses higher capacity muxponders from the start, which are considerably more expensive. The flexible-grid migrate scenario is more expensive than the fixed grid scenario, as more expensive nodes are installed from the start.

When looking at the cost breakdown for different installation scenarios (Fig. 3), it is clear that the capital expenditures for regenerators and muxponders comprise the largest share of the total cost, around 95\% for both scenarios. The cost for nodes, amplifier and energy is

TABLE II

TOTAL COST FOR THE INSTALLATION OPTIONS

\begin{tabular}{cc}
\hline \hline Scenario & Cumulative discounted cost \\
\hline Fixed grid & $30.020 \mathrm{SCU}$ \\
Flexible-grid & $75.710 \mathrm{SCU}$ \\
Flexible-grid migrate & $30.663 \mathrm{SCU}$
\end{tabular}

negligible.

With this result, the operator would clearly choose to install a fixed grid core network, since this technology choice clearly is the most cost efficient. However, what would happen if traffic growth would be higher than expected? This result is based on the assumption that no migration from fixed grid to flexible-grid is required, but it was already indicated that traffic growth might force operators to undertake this migration when spectrum becomes scarce. This will be studied in the following section.

\section{REAL OPTIONS THINKING IN TELECOM INFRASTRUCTURE}

The feasibility of telecom infrastructure investments is typically assessed through a techno-economic analysis. This methodology covers input collection, cost modelling and business case analysis [9]. However, this methodology cannot cover the impact of uncertainty and flexibility [10].

But this uncertainty and flexibility will generally have a large impact on the viability of the business case. Traffic growing at a faster pace than expected will result in the installation of higher capacity muxponders and regenerators earlier in the project, or even the need to migrate to flexible-grid. 


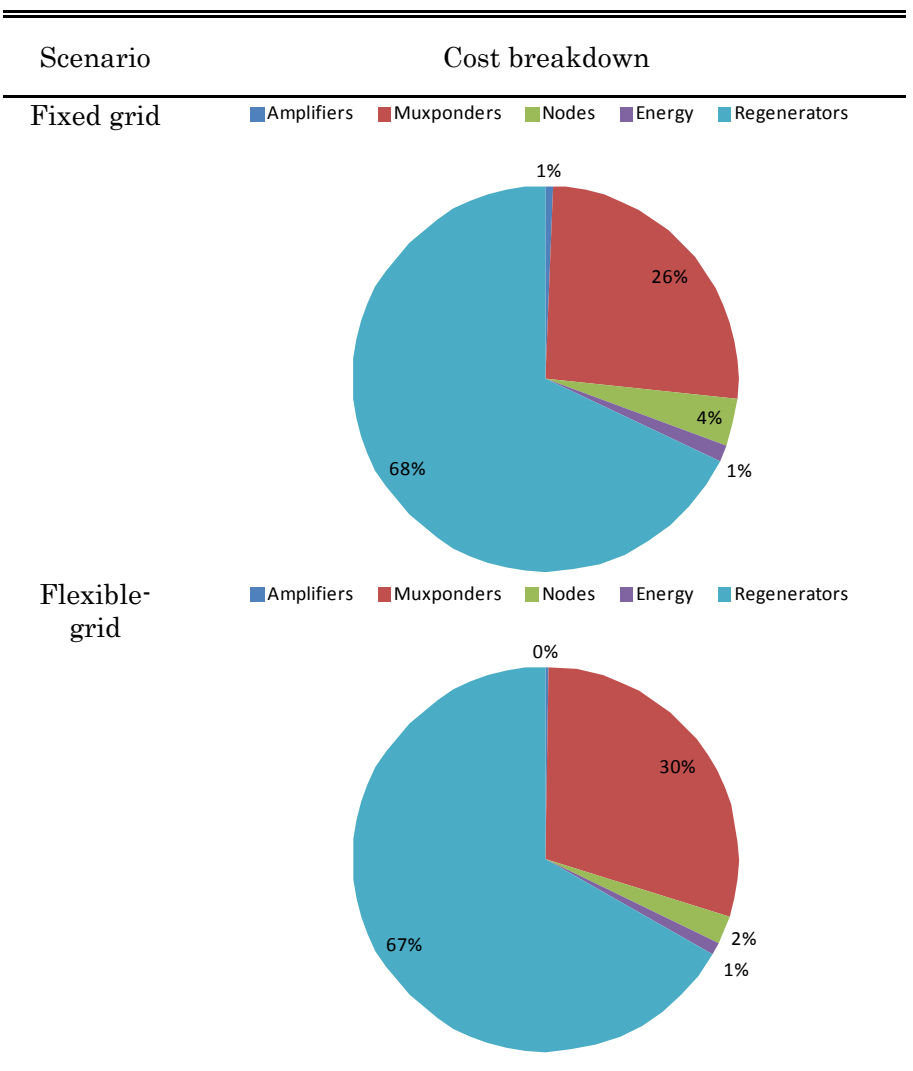

Fig. 3. Cost breakdown for different scenarios

To capture the impact of uncertainty and flexibility, real option thinking offers a solution. To be eligible for e real option analysis (ROA), the case must meet three conditions, namely uncertainty, flexibility and timing.

1. Uncertainty

Assumptions made in the techno-economic analysis come with a certain degree of uncertainty. If the estimate of this assumption turns out to be wrong in the future, the result of the investment decision can be severely impacted.

2. Flexibility

The network operator is flexible in the path he chooses to follow.

3. Phased decision

Typically, an option comes at some cost (option price). An initial (smaller) investment is needed in order to guarantee the option to choose at a later point in time.

Real option valuation allows identifyig trade-offs in the investment decision. 'Buying' the option at the initial installation of the network results in a higher initial investment cost, but can result in lower follow-up investments in the future.

\section{A. Uncertainty}

There are various potential sources of uncertainty in the case presented here. These can be linked either to future traffic or the future cost.

- The bandwidth growth evolution is the major uncertainty in this case. The initial traffic matrix is clear, but its evolution in time is bound to an uncertain evolution. What is this expected evolution? And is there any indication of the uncertainty on the expected traffic evolution?

- Current flexible-grid equipment, muxponders and regenerators are still a new technology, and there are still some risks related with using them. For example, it is not very good at distinguishing between wavelengths. The equipment will become chepaer and more trustworthy in the future. As such, the future maintenance and replacement costs of this equipment is uncertain.

- Technological evolution can lead to cost erosion in flexible-grid equipment. While the application of the learning curve can model this cost erosion, it is still required to estimate this yearly cost decrease upfront when making the investment decision.

- Early installation of a flexible-grid network is more expensive, since the equipment has not hit mass market yet, or is not available yet.

\section{B. Managerial flexibility}

A graphical overview of the managerial flexibility can be found in Fig. 2. In case of the migration scenarios, operators have to decide on the upgrade of their core network. Three possible scenarios were taken into account in this study.

- Flexible-grid scenario

The operator installs flexible-grid ready equipment. If traffic grows faster then expected, the operator is ready for it. If it does not gorw fast, a lot of money was spent in vain.

- Fixed grid migrate scenario

The operator does not install flexible-grid ready equipment. If traffic follows the expected growth path, then this solution will be the most cost efficient, as was indicated in Section II. If traffic grows faster than expected, the operator will end up either losing money not being able to route all traffic or they will be putting in a next generation DWDm network (presumably flexiblegrid ready this time) earlier than they would have needed to, which will lead to additional costs

- Flexible-grid migrate scenario

The operator buys the option to migrate to flexible-grid by installing flexible-grid capable nodes, but he continues to use fixed grid muxponders and regenerators. In case the traffic grows faster than expected, the operator is ready for it and the investment in flexible-grid ready nodes can be avoided. In case traffic grows at its expected growth rate, the operator can use the less expensive fixed grid muxponders.

In the flexible-grid scenario the operator looses all its flexibility. The core network is fully upgraded towards flexible-grid, and there is no way back. The same goes for the fixed grid migrate scenario. Under high traffic growth, the operator has no other choice than to install flexible-grid. The flexibility is present in the last scenario. The upgrade towards full flexible-grid can be performed when necessary. 
In addition, he does not have to decide on this upgrade today, but can do this when the uncertainty surrounding future traffic and flexible-grid equipment is reduced.

Other options are available as well. The operator could overbuild, or install a fixed grid network with larger channel spacing. When an operator performs this investment analysis to indicate its best investment options, these should be included as well. However, as this paper aims at introducing real options, these options were left out. Our analysis tries to offer a methodological approach to investment decisions in core networks, not at indicating the one-fits-all solution, as the optimal solution is case dependent.

\section{Phased decision}

Typically an option-based investment is characterized by a phased decision. One makes a small initial investment (buying the option at the option price) which allows a followup investment later on leading to additional revenues (exercising the option for the exercise price) or deciding not to go forward with the follow-up investment in case the market conditions do not turn out favourable.

In this case, such an expansion option can be seen in the flexible-grid migrate scenario. The operator makes an additional initial investment, i.e. the installation of flexiblegrid capable nodes instead of standard fixed grid nodes. Initially the operator uses standard (cheaper) fixed grid muxponders, but when the traffic grows faster than expected, a follow-up investment in flexible-grid muxponders can be done. In this case, the operator saves the replacement cost for new nodes.

The other option that can be found in this case is the option to wait. By initially installing fixed grid equipment and transponders, the operator can wait and decide at every point in time to migrate to flexible-grid, depending on the bandwidth growth and technological evolution. The longer the investment can be postponed, the higher the value of the option to wait. However, the value of waiting can also be found in the fixed grid - migrate scenario. Here the operator waits with the installation of the flexible-grid muxponders and nodes.

When the business case meets the three conditions, a ROA can be performed. The methodology for this ROA consists of four steps, and is described in more detail in [10]. First, a standard NPV analysis is performed for the case. This step has been conducted in Section II. The second and third step identify the uncertainties and flexibility respectively. This has been performed while checking the three conditions. Finally, a ROA concludes by performing the extended analysis in step four. Typically, a ROA consists of performing a Monte Carlo analysis on the static NPV analysis, including uncertainty on the input parameters and checking their impact on the final result.

\section{IMPACT OF TRAFFIC GROWTH UNCERTAINTY}

It was already indicated above that traffic growth is a major uncertainty when performing dimensioning studies, and it has a large impact on the expected result. If traffic grows at a faster pace, it would require the installation of additional muxponders and regenerators to provision for parallel paths earlier. As a result, the total available spectrum will be reduced or even run out, requiring a migration towards flexible-grid in case the operator chose a fixed grid installation.

Under the expected traffic growth of $37 \%$, this migration towards flexible-grid could be postponed to the next reinstallation time, in five years. However, if traffic grows faster than expected, this installation will be required earlier, resulting in an additional investment cost. Here, it is assumed that if total traffic grows by 500\%, such a migration would be required, which is in line with the current capacity limits of the UK core network. Although this threshold is inserted artificially, it allows assessing the impact of traffic growth uncertainty. Under the basic assumption of $37 \%$ growth p.a., this threshold is not exceeded within the evaluation period of five years for the majority of the links. However, links already currently experiencing high traffic would need to be migrated anyway. The advantage of this migration scenario is that it allows a gradual migration towards flexible-grid, while the operator loses all flexibility in the flexible-grid scenario.

Under these assumptions, the advantages of the Fixed grid migration scenario are clear. Since only a small number of links would require a migration, the cost increase is negligible compared to the investment in a full flexible-grid network. But what would be the impact on the total cost for both scenarios under other traffic growth conditions? When the flexible-grid migration scenario is considered, the same rationale as for the fixed grid migrate scenario holds. However, as the nodes are installed flexible-grid ready, the migration will come at a lower cost, as only an investment in muxponders and regenerators will be required, not in nodes.

To indicate the impact of this uncertainty on the analysis, a scenario analysis for the different migration paths to flexible-grid is presented below (Fig. 4). It is clear that for the lower traffic growth scenarios, the installation of Fixed grid DWDM equipment is to be preferred compared to the flexible-grid migrate installation, as was also concluded from the standard techno-economic analysis. When no migration is required, the operator would clearly opt for the cheaper fixed grid installation. However, as is clearly visible from the high traffic growth scenarios, the total investment cost for the migrate scenarios rises, while the flexible-grid scenario is traffic independent. Although the flexible-grid

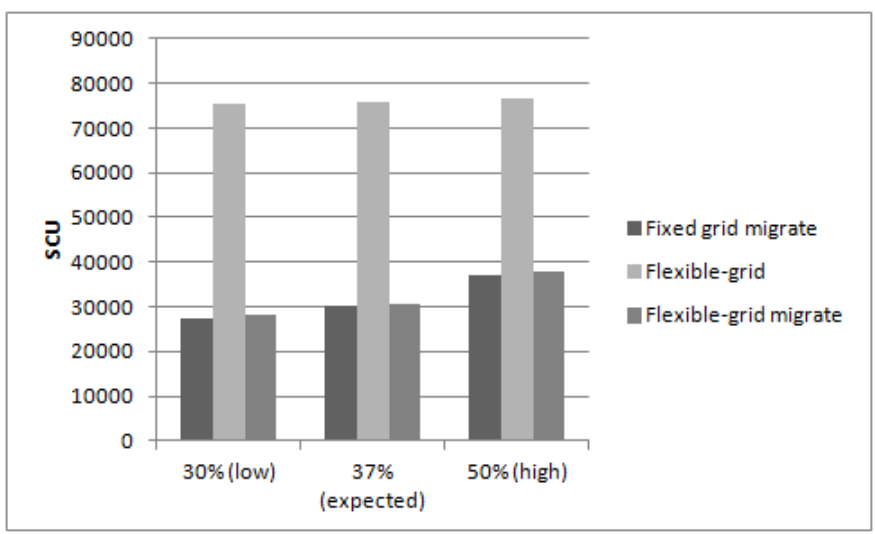

Fig. 4. Impact of uncertainty on investment cost 
migrate scenario offers a cheaper migration in the future, this does not result in a lower total investment cost during the project lifetime. It is thus to be expected that flexibility does not pay off in this case.

In order to indicate the impact of uncertainty clearer on the result, the scenario analysis is extended towards a real option analysis. The traffic growth is now distributed triangularly between $30 \%$ and $60 \%$, with $37 \%$ as the most likely. The impact of this uncertainty, and the resulting value of flexibility in the migration decision in time on the results for the migrate scenarios can be found in Fig. 5 . From the cost distributions, it is clear that the traffic uncertainty has a major impact on the cumulative distributed cost (CDC) evaluation of both scenarios. For both scenarios, an increase in the traffic growth results in an increase of the total cost. However, when comparing both cost distributions, it is clear that the fixed grid migrate scenario remains the most cost efficient. The analysis was also performed for the flexible grid scenario. As the total cost is always significantly higher than the cost for the other two scenarios, they are not depicted on the figure.

Conducting the ROA thus indicated that uncertainty has a clear impact on the CDC evaluation, but there is no value in buying the option for a cheaper migration in the future.

\section{CONCLUSIONS}

The translation of high growth in network demand in the access networks is putting pressure on the core networks. In

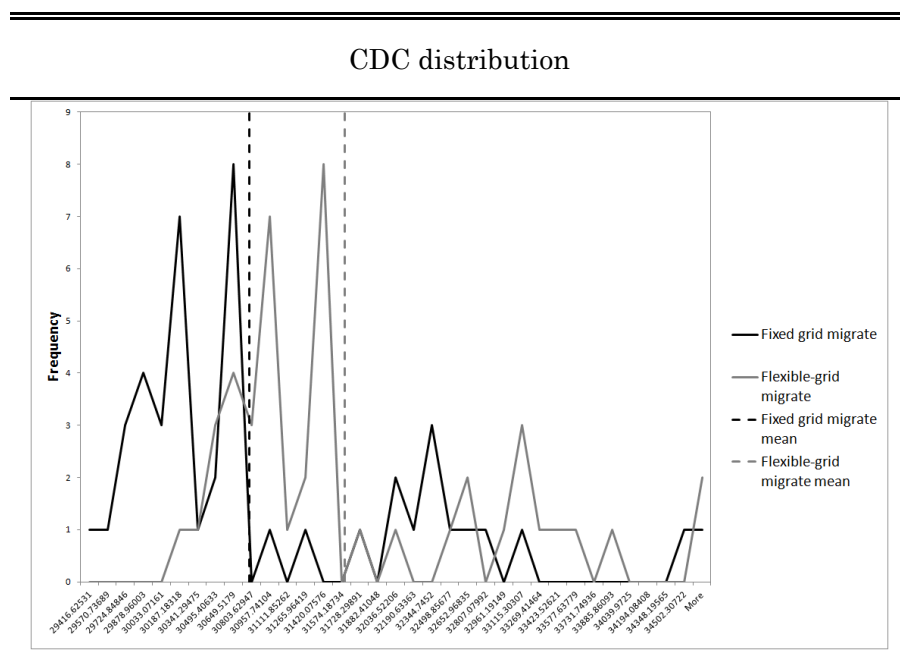

Fig. 5. Cost evolution under uncertainty for the different scenarios

order to maintain profitability, operators are continuously looking to reduce the cost per transported bit. Today, core networks are based on fixed grid DWDM system, making use of parallel light paths between core routers. However, in light of the expected traffic increase, the underlying assumption that spectrum availability poses no restriction is being challenged. As a solution to increase spectral efficiency, the flexible-grid concept has been introduced recently.

As equipment needs to be replaced often, operators will have to make the decision to migrate to flexible-grid within the coming years. This migration decision is based on various aspects, which can have a different influence. Uncertain traffic growth and performance of equipment are only two of those aspects.

Since the operator aims to reduce costs, the translation of these influences on the expected investment needs to be assessed. In this paper, such a techno-economic analysis of the replacement investment in core network equipment is performed. It is shown how uncertain future traffic growth evolutions impact the investment decision. Initially, no migration is required, but uncertain traffic growth largely impacts the migration need and the associated total investment cost. However, since operators can flexibly adapt to changing conditions, reducing risk and investment, a real option analysis was performed to capture the value of this flexibility. Flexibility should be taken into account when such an investment decision is made. Although no value of waiting was identified here, the results are case specific and dependent on a broad range of input factors.

As such, the results of the case study only hold for this specific case. Including other options, like overbuilding or $100 \mathrm{GHz}$ spacing fixed grid should be taken into account if this analysis is performed by operators. In addition, the case focused on a dense Western European network. Other network topologies will have an impact on the outcome of the analysis, and on the preferred installation by the operator.

\section{ACKNOWLEDGMENT}

The research leading to these results has received funding from the European Community's Seventh Framework Programme FP7/2007-2013 under grant agreement $n^{\circ} 247674$ (STRONGEST project).

\section{REFERENCES}

[1] Spectral grids for WDM applications: DWDM frequency grid, ITU-T Recommendation G.694.1, (pre-published, 2012)

[2] O. Pedrola, a. Castro, L. Velasco, M. Ruiz, J. P. FernándezPalacios, and D. Careglio, "CAPEX Study for a Multilayer IP/MPLS-Over-Flexgrid Optical Network," Journal of Optical Communications and Networking, vol. 4, no. 8, p. 639, Jul. 2012.

[3] F. Rambach, B. Konrad, L. Dembeck, U. Gebahrad, M. Gunkel, M. Quagliotti, L. Serra, V. Lopez, "A Multi-Layer Cost Model for Metro/Core Networks", Journal of Optical Communications and Networking (JOCN), 5 (3), 210-225 (2013)

[4] Efficient and optimized network architecture: Requirements and reference scenarios, STRONGEST D2.1

[5] Copeland, T. E., \& Keenan, P. T. "How much is flexibility worth?" McKinsey Quarterly, (2), 38-50 (1998).

[6] Final results on novel packet based petabit transport networks fulfilling scalability, quality, cost and energy efficiency requirements, STRONGEST D2.4

[7] S. Gringeri, B. Basch, V. Shukla, R. Egorov, and T. J. Xia, "Flexible architectures for optical transport nodes and networks," IEEE Communications Magazine 48 (7), 40-50 (2010).

[8] B.T. Olsen and K. Stordahl, "Models for forecasting cost evolution of components and technologies", Telektronikk 4.04, pp. 138-148, 2004.

[9] Verbrugge, S., Casier, K., Van Ooteghem, J., \& Lannoo, B. (2008). Practical steps in techno-economic evaluation of network deployment planning. IEEE Globecom, Tutorial, 11., available 
http://www.ibcn.intec.ugent.be/sites/default/files/docs/IBCN_T E_WhitePaper_200911.pdf

[10] M. Tahon, S. Verbrugge, P. J. Willis, P. Botham, D. Colle, M. Pickavet, P. Demeester, "Real Options in Telecom Infrastructure projects - A Tutorial", IEEE Communications: Surveys and Tutorials, Accepted for publication

Mathieu Tahon graduated as Master in Applied Economics, option Finance in 2009 at Ghent University. He joined the IBCN research group of the Department of Information Technology as $\mathrm{PhD}$ student in August 2009, at the same university. He is affiliated with the techno-economic research cluster, where he performs research on the application of advanced evaluation techniques in broadband network rollout (both fixed and wireless) and new service introduction (smart meters, electric vehicles). He specifically focuses on the use of real option and competition modeling in the economic evaluation.

He was involved in various national and European research projects, including the European FP7 ICT-STRONGEST project and the national IBBT-ICON TERRAIN, where he led the work package on extended evaluation techniques. He is currently working within the European FP7 project ICT-TREND, studying cooperative models in wireless networks in order to reduce cost and energy consumption.

Sofie Verbrugge received an MSc degree in computer science engineering from Ghent University (Ghent, Belgium) in 2001. She obtained the $\mathrm{PhD}$ degree from the same university in 2007 for her thesis entitled "Strategic planning of optical telecommunication networks in a dynamic and uncertain environment".

She is currently working as a researcher affiliated to iMinds, a research institute to stimulate ICT innovation in Flanders, where she is a coordinator for the techno-economic research within the Internet Based Communication Networks and Services group (IBCN). Her main research interests include infrastructure as well as operational cost modeling, telecom service and network deployment planning, advanced evaluation techniques including real options and game theory. She has been involved previously in several European as well as national research projects in these domains, including the COST-action Econ@tel. She led the work package on "Business modeling" with the European FP7 project ICT-OASE and is currently working within the FP7 project ICTFlamingo.

Didier Colle received a M. Sc. degree in electrotechnical engineering (option: communications) from the Ghent University in 1997. Since then, he has been working at the same university as researcher in the department of Information Technology (INTEC). $\mathrm{He}$ is part of the research group INTEC Broadband Communication Networks (IBCN) headed by prof. Piet Demeester. His research led to a Ph.D degree in February 2002. He was granted a postdoctoral scholarship from the Institute for the Promotion of Innovation through Science and Technology in Flanders (IWT-Vlaanderen) in the period 2003-2004. Currently, he is co-responsible for the research cluster on network modelling, design and evaluation and is coordinating the research on fixed internet architectures and optical networks.

His research deals with design and planning of communication networks. This work is focussing on optical transport networks, to support the next-generation Internet. Up till now, he has actively been involved in several national and international research projects. His work has been published in more than 250 scientific publications in international conferences and journals.

Mario Pickavet received an M.Sc. and Ph.D. degree in electrical engineering, specialized in telecommunications, from Ghent University in 1996 and 1999, respectively. Since 2000, he is professor at Ghent University where he is teaching courses on discrete mathematics, multimedia networks and network modeling.
$\mathrm{He}$ is co-leading the research cluster on Network Modeling, Design and Evaluation (NetMoDeL) covering 4 research topics: Fixed internet architectures and optical networks, techno-economic studies, green-ICT and design of network algorithms (DNA). In this context, he is currently involved in several European and national projects.

He has published about 300 international publications, both in journals (IEEE JSAC, IEEE Comm. Mag., Journal of Lightwave Technology, ...) and in proceedings of conferences. He is co-author of the book 'Network Recovery: Protection and Restoration of Optical, SONET-SDH, IP, and MPLS'.

Piet Demeester is professor in the faculty of Engineering at Ghent University. He is head of the research group "Internet Based Communication Networks and Services" (IBCN) that is part of the Department of Information Technology (INTEC) of Ghent University. He is also leading the Future Internet Department of the strategic research center iMinds. He is Fellow of the IEEE.

The IBCN group is focusing on several advanced research topics: Network Modeling, Design \& Evaluation; Mobile \& Wireless Networking; High Performance Multimedia Processing; Autonomic Computing \& Networking; Service Engineering; Content \& Search Management and Data Analysis \& Machine Learning."

Paul Wright is a Senior Optical Network Professional at British Telecom working on research into next generation optical core transport networks. He joined BT in 2006 after graduating from the University of York with a first class MEng degree in Computer Systems and Software Engineering.

Since joining BT, he has worked in many areas of optical networking including traffic and multilayer network modelling, alien wavelengths, Flexgrid and SDN research. He has contributed to the STRONGEST and IDEALIST EU collaborative projects. He is a member of the BCS and IEEE.

Andrew Lord is an Optical Specialist at BT, where he is currently responsible for directing research into optical access and core transport and networks as well as copper access and network modeling. He received his B.A. (Hons) degree in Physics from Oxford University in 1985, and joined BT after graduating. He has worked on all implementations of DWDM technology since then, including large subsea systems such as TAT14 as well as national and Ministry of Defence DWDM networks. He has helped lead the EU collaborative projects NOBEL and STRONGEST, and currently serves on the technical subcommittees of several conferences including OFC, where he is the Core Networks chair for the 2013 conference. Mr. Lord is a member of the Institute of Physics. 